Editorial

\title{
An introduction to field experiments in economics
}

\section{Introduction}

The major empirical challenge for economists is going beyond correlational analysis to provide insights on causation. While economics has been served well by using precise models and econometric techniques for answering causal questions using variations in naturally occurring data, an important recent development to provide insights on causation is the expanding use of controlled laboratory experimentation. Under this approach, identification of causation is typically achieved via randomization. In this manner, randomization is an instrumental variable that is exogenous by definition.

Perhaps this is the reason why the experimental method has gained momentum within economics over the past several decades. Holt (2005) documents that experimental economics is a "boom industry," showing that publications using the methodology were almost non-existent until the mid-1960s and surpassed 50 annually for the first time in 1982; by 1998 there were more than 200 experimental papers published per year. Using a slightly different approach to summing such publications, I constructed Fig. 1, which tells a similar story but extends the time-frame and focuses on a different journal classification scheme.

To complement lab and naturally occurring data, the past decade has witnessed a significant surge in studies that gather data via field experiments. Such experiments are a useful marriage between laboratory and naturally occurring data in that they represent a mixture of control and realism not usually achieved in the lab or with naturally occurring data. In this regard, field experiments represent a useful bridge between data gathered in the lab and uncontrolled field data, permitting the analyst to address questions that heretofore were quite difficult to answer.

In the next Section, I detail the various types of field experiments and summarize the contents of this special issue on field experiments. Section 3 concludes.

\section{Types of field experiments}

Three main types of field experiments have emerged in the past decade within economics: artefactual, framed, and natural field experiments (see Harrison and List, 2004). Fig. 2 highlights these field experiment types and how they bridge lab experiments and some popular econometric techniques used to model naturally occurring data.

Starting at the left portion of Fig. 2, I present artefactual field experiments, which share many of the qualities of conventional lab experiments, but use a subject pool from the population of interest. This special issue on field experiments contains several excellent examples of how one might use artefactual field experiments to lend insights into important economic phenomena. Two studies that focus on measuring risk preferences, Masclet et al. and Harrison et al., showcase this particular methodology in a clever manner.

In Masclet et al., the authors make use of a multiple price listing approach to explore subjects' propensity to take on risk. The subject pool varies from students to salaried workers to the self-employed. Treatment variations include a comparison across individual choices and group choices, where subjects are in anonymous groups of three, and a unanimous decision rule determined which lotteries were chosen. Empirical results suggest that groups choose the safer options more often than individuals and that socio-demographic variables are quite important in predicting risk attitudes. For example, those who are self-employed tend to be less risk averse than others. Whether such relationships are due to treatment or selection effects is difficult to address, but the correlations brought to the fore are interesting in their own right.

In Harrison et al., the authors use a similar experimental approach both to measure the risk preferences of a representative sample of Danish citizens and to explore whether randomization bias affects inference drawn. Randomization bias is a situation wherein the experimental sample is different from the population of interest because of randomization. For instance, it is commonly known in the field of clinical drug trials that persuading patients to participate in randomized studies 


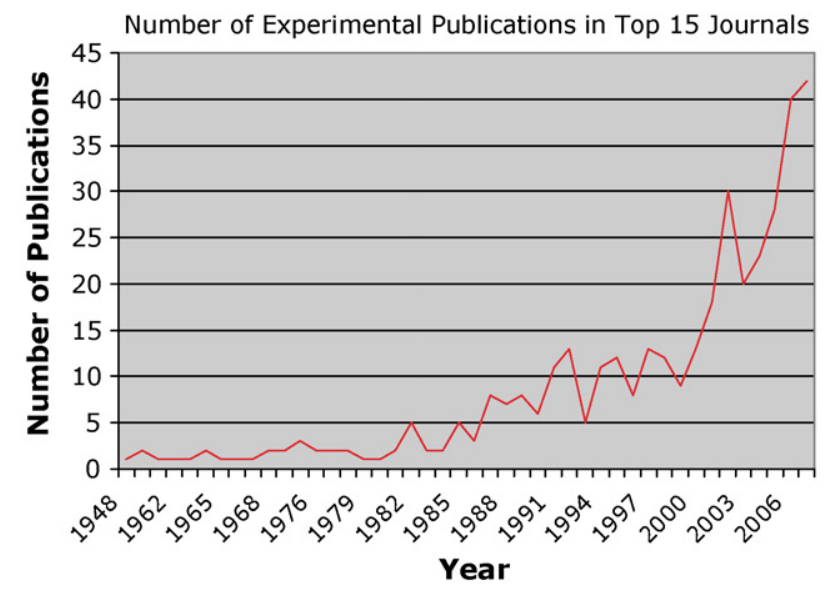

Note: Figure only includes experimental publications in the top 15 economic journals, as defined by Kalaitzidakis et al. (2003)

Fig. 1. Growth in the experimental method. Note: Figure only includes experimental publications in the top 15 economic journals, as defined by Kalaitzidakis et al. (2003).

is much harder than persuading them to participate in non-randomized studies. To my knowledge, Harrison et al. is the first experiment to explore this important issue in economic games. Amongst a slew of findings, they report that (p. 1), "randomization bias is not a major empirical problem for field experiments of the kind we conducted."

Of course, artefactual field experiments are not restricted to tests within the realm of risky decision making. The novel work of Burks et al. and Cummings et al. represent key examples. In Burks et al., the authors examine the behavior of students and bicycle messengers from Switzerland and the U.S. in sequential prisoner dilemma games. The differences in subject groups are important because in some cases they receive performance pay in the workplace and in others they receive fixed wages. A key insight gained in the experiment is that messengers at firms that pay for performance are less cooperative than those messengers who are paid at an hourly rate. Ancillary evidence suggests that this is due more to treatment than selection. A further result is that messengers act in a manner that is more cooperative than students. This type of result has become a "stylized" one in this literature (see List, 2004a; Carpenter et al., 2005, 2008; Holm and Nystedt, 2005; Bellemare and Shearer, 2007; Sutter, 2007; Sutter and Kocher, 2007; Gächter and Herrmann, 2007; Güth et al., 2007).

Cummings et al. (2009) tackle a much different question when they run an artefactual field experiment in Botswana and South Africa to explore what factors influence tax compliance. The major underlying premise of the paper is that crosscountry differences in government institutions and citizens' faith in such institutions influence tax morale and compliance levels. Consonant with this hypothesis, the authors report that citizens of Botswana are more tax compliant than citizens in South Africa, independent of the experimental parameters. I interpret these results as potentially providing insights into the underlying sources of tax compliance differences. Clearly these are suggestive results, and care should be taken when making inference from the data patterns observed because several important factors vary across the two societies. However, the study provides important insights, and points scholars to fertile areas for future research.

Moving closer (on some dimensions) to how naturally occurring data are generated, Fig. 2 highlights "framed field experiments," which are the same as an artefactual field experiment except that they incorporate important elements of the context of the naturally occurring environment with respect to the commodity, task, stakes, and information set of the subjects. It is important to note that framed field experiments, like lab experiments and artefactual field experiments, are conducted in a manner that ensures subjects understand that they are taking part in an experiment with their behavior subsequently

Controlled Data Naturally-Occurring Data

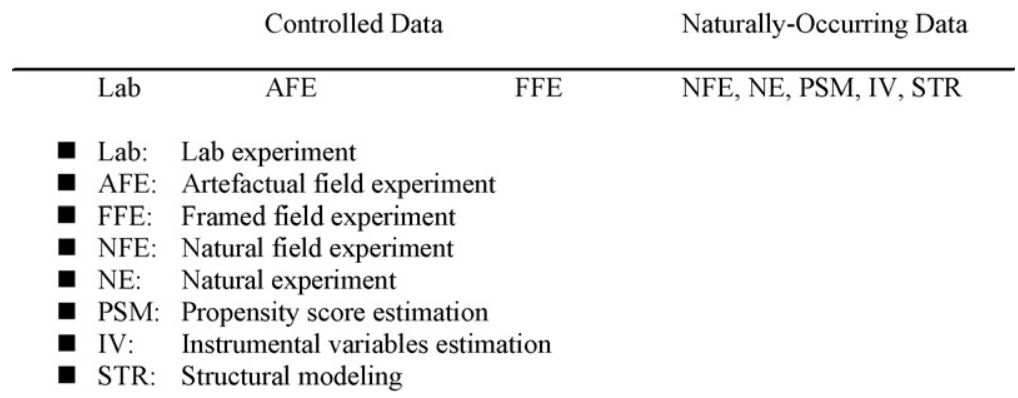

Fig. 2. A field experiment bridge. 
recorded and scrutinized. This type of experiment is important in the sense that a myriad of factors might influence behavior, and by progressing slowly toward the environment of ultimate interest one learns about whether, and to what extent, such factors influence behavior. Framed field experiments are a cousin of the social experiments of the 20th century, which included government agencys' attempts to evaluate programs by deliberate variations in agency policies. Such large-scale social experiments included employment programs, electricity pricing, and housing allowances (see Levitt and List, 2008 for further discussion).

One recent innovative framed field experiment is published in this special issue: Velez et al. In this thoughtful piece, the authors examine behavior of agents from multiple sites in Colombia. The authors have a large lot of such agents play a common pool resource game. The agents have extensive experience fishing and drawing down a renewable resource in their domains of expertise, lending the study a degree of naturalness afforded by framed field experiments. The study further separates itself by its ability to test alternative models of individual behavior, taking advantage of exactly the control that the experimental method provides. In the end, across all three regions a model that balances pure self-interest with a preference for conformity describes decisions on average. Other popular models are found to be inconsistent with the received experimental data.

Finally, the "last frontier" of field experiments is denoted a natural field experiment in Fig. 2. Natural field experiments are those experiments completed in situations where the environment is such that the subjects naturally undertake these tasks and where the subjects do not know that they are participants in an experiment. Therefore, they neither know that they are being randomized into treatment nor that their behavior is subsequently scrutinized. Such an exercise is important in that it represents an approach that combines the most attractive elements of the lab and naturally occurring data: randomization and realism. In addition, it is difficult for people to respond to treatments they do not necessarily know are unusual, and of course they cannot excuse themselves from being treated (for effects of such factors see Levitt and List, 2007). Hence, many of the limitations ascribed to the other approaches above are not an issue when making inference from data generated by natural field experiments.

This special issue on field experiments contains two thoughtful natural field experiments: Gächter et al. and Lahey and Beasley. In Gächter et al., the authors examine whether economists are susceptible to framing effects. Using an ingenious design that took advantage of an opportunity that the authors had as conference organizers, they randomized subjects into a positive frame (discount for early registration) or a negative frame (penalty for late registration). In aggregate, it is difficult to find an effect of the framing manipulation, but when the authors parse the data by experience in the profession, they find that junior economists are quite susceptible to the frame whereas the senior economists are not. This result has important implications in both a positive and normative sense, and is consonant with insights gained from the field experiments reported in List (2003, 2004c).

Lahey and Beasley provide a nice example of how a natural field experiment can be used to explore issues associated with discrimination. They begin with a methodological discussion of the traditional audit approach and demonstrate their proposed methodology by generating a small dataset that explores age discrimination. In the study, they match 35 -year-olds with 62-year-olds and send resumes to firms in Boston, MA. They report that the template computerization of a resume can efficiently increase sample size. Further, they find some evidence that younger applicants are more likely to be called back for an interview than are older applicants. This result is important in its own right, and the next step in this research agenda is to understand the nature of such discrimination.

\section{Epilogue}

While the use of field experiments has increased rapidly in the past decade, each of the approaches in Fig. 2 has important strengths and limitations. The various empirical approaches should be thought of as strong complements-much like theory and empiricism, and combining insights gained from each of the methodologies will permit scholars to develop a deeper understanding of social science. This special issue does not contain studies that combine data across the field experimental bridge in Fig. 2, but some have surfaced recently. For example, related to the natural field experiment of Lahey and Beasley, I present a series of field experiments in List (2004b), from artefactual to framed to natural, in an actual marketplace to provide an empirical framework for disentangling the major theories of discrimination: animus and statistical discrimination.

In closing, I would like to thank the anonymous referees for their insightful comments. While they are rarely recognized properly, they performed remarkably well, helping me choose the best manuscripts; hence, thanks! Clearly, the manuscripts in this special issue highlight that field experiments take many shapes and forms, and all might not fit neatly into the guideposts in Fig. 2. However, I hope that these guideposts permit a more informative discussion of how field experiments can be used to yield a deeper understanding of economic science. I trust that the papers in this special issue will play a role in this regard as well.

\section{References}

Bellemare, C., Shearer, B., 2007. Gift exchange within a firm: evidence from a field experiment. CIRPÉE Working Paper 07-08

Carpenter, J., Verhoogen, E., Burks, S., 2005. Comparing students to workers: the effects of stakes, social framing, and demographics on bargaining outcomes. In: Carpenter, J., Harrison, G., List, J.A. (Eds.), Field Experiments in Economics. JAI Press, Stamford, CT, pp. 261-290.

Carpenter, J., Connolly, C., Myers, C.K., 2008. Altruistic behavior in a representative dictator experiment. Experimental Economics 11, $282-298$. 
Gächter, S., Herrmann, B., 2007. The limits of self-governance when cooperators get punished: experimental evidence from urban and rural Russia. CeDEx Discussion Paper No. 2007-11.

Güth, W., Schmidt, C., Sutter, M., 2007. Bargaining outside the lab: a newspaper experiment of a three-person ultimatum game. The Economic Journal 117, 449-469.

Harrison, G.W., List, J.A., 2004. Field experiments. Journal of Economic Literature 42, 1009-1055.

Holm, H.J., Nystedt, P., 2005. Intra-generational trust-a semi-experimental study of trust among different generations. Journal of Economic Behavior \& Organization 58, 403-419.

Holt, C.A., 2005. Markets, Games and Strategic Behavior: Recipes for Interactive Learning. Addison-Wesley, Boston.

Kalaitzidakis, P., Mamueas, T.P., Stengos, T., 2003. Rankings of academic journals and institutions in economics. Journal of the European Economic Association $1,1346-1366$

Levitt, S.D., List, J.A., 2007. What do laboratory experiments measuring social preferences tell us about the real world? Journal of Economic Perspectives 21 (2), 153-174.

Levitt, S.D., List, J.A., 2008. Field experiments in economics: the past, the present, and the future. NBER Working Paper No. w14356.

List, J.A., 2003. Does Market Experience Eliminate Market Anomalies? Quarterly Journal of Economics 118, 41-71.

List, J.A., 2004a. Young, selfish, and male: field evidence of social preferences. Economic Journal 114, 121-149.

List, J.A., 2004b. The nature and extent of discrimination in the marketplace: evidence from the field. Quarterly Journal of Economics 119, 49-89.

List, J.A., 2004c. Neoclassical Theory Versus Prospect Theory: Evidence from the Marketplace, Econometrica, 72, 615-625.

Sutter, M., 2007. Outcomes versus intentions: on the nature of fair behavior and its development with age. Journal of Economic Psychology 28, 69-78

Sutter, M., Kocher, M., 2007. Trust and trustworthiness across different age groups. Games and Economic Behavior 59, $364-382$.

John A. List*

Department of Economics, The University of Chicago and NBER, 1126 East 59th Street, Chicago, IL 60637, United States

* Tel.: +1 773702 9811; fax: +1 7737028490

E-mail address: jlist@uchicago.edu URL: http://home.uchicago.edu/ jlist/

29 October 2008

Available online 22 January 2009 